\title{
Mobile Healthcare Technology for People with Disabilities amid the COVID-19 pandemic
}

\author{
Cathy Mae Dabi Toquero ${ }^{1 *}$
}

${ }^{1}$ College of Education, Mindanao State University, General Santos City, PHILIPPINES
${ }^{*}$ Corresponding Author: cathymaetoquero@gmail.com

Citation: Toquero, C. M. D. (2021). Mobile Healthcare Technology for People with Disabilities amid the COVID-19 pandemic. European Journal of Environment and Public Health, 5(1), em0060. https://doi.org/10.29333/ejeph/8551

\section{ARTICLE INFO}

Received: 24 Jun. 2020

Accepted: 28 Jul. 2020

\begin{abstract}
People with disabilities are often deprived of their rights for quality healthcare during an emergency. The reasons for the deprivations are due to a lack of specialized healthcare that can cater for their health essentials and due to a lack of policies that protect their health rights. However, people with disabilities should be safeguarded since they tend to be the most vulnerable during times of crisis. In this regard, technology can empower people with disabilities through the use of designed mobile healthcare technologies or mhealth apps that are specialized for their health needs which they can use during the global emergency.
\end{abstract}

Keywords: COVID-19, mobile health, smartphone applications, disability

Digital technology has empowered people to obtain the latest results and advancements on the race for the vaccine against the novel coronavirus. Though studies exist that focused on the use of mobile devices for educational purposes, these studies (Godwin-Jones, 2011; Oberg and Daniels, 2013; Sung, Chang, and Liu, 2016) are not specialized for people with disabilities. Likewise, as the general population are given provisions for seeking online health services, people with disabilities are often left out as provisions for mobile health services specialized for their healthcare needs are insufficient. Likewise, very few of the mHealth apps are specifically designed for people with disabilities and as a result, they have difficulties in the utilization of these mHealth apps (Zhou, Saptono, Setiawan, and Parmanto, 2020). The lack of appropriate provisions for mobile healthcare during this pandemic can lead to health disparities for people with disabilities.

However, the integration of digital health interventions can supplement assessment technologies to support the healthcare needs of people with disabilities. Specifically, the utilization of mobile healthcare can pave the way to empower people with disabilities for their healthcare essentials during this global health emergency. The findings of a study (Jones, Morris, and Deruyter, 2018) demonstrate that opportunities arise on the use of mobile healthcare as emerging solutions for the health needs of people with disabilities (Table 1). The modification of the table focused on a specialized mhealth technology for a specific disability.

The use of mobile healthcare technology among people with disabilities can also alleviate the social and health disparities. They can access healthcare interventions that can overcome barriers to inaccessibility of health information and prevention measures. Information and Communication Technology (ICT) developers should create health-related devices that have the lens of people with disabilities at the focal point. This means configuring mobile healthcare technologies that are user-friendly to them.

Moreover, the devices should have functionality that can have speech, voice, text, video, and face recognition and other multiple assistive features that are accessible even in remote interactions while considering portability, efficiency and affordability for people with disabilities (Thompson, 2018). A personalized design can be a key to approaching the challenges in accessibility (Yu, Parmanto, Dicianno, Watzlaf, and Seelman, 2017; Yu, Parmanto, and Dicianno, 2019). By doing so, people with disabilities can access telemedicine experience as they obtain supervision from medical experts for diagnostics and health interventions. They can also easily perform self-management activities and communicate with their assigned medical professionals (Yu et al., 2019). A study (Setiawan, Zhou, Alfikri1, Saptono, Fairman, Dicianno, and Parmanto, 2019) also concluded that the use of the mHealth app as a novel method can support the diverse needs through self-management for a personalized self-care needs of people with disabilities.

People with disabilities can gain confidence in the health system when "disability rights advocates and health care leaders [can] work together to (...) save the most lives, protect the equal worth of all persons, and enhance communities' capacity to heal in the wake of a once-in-a century pandemic" 
Table 1. mHealth apps available on resources websites for people with disabilities (Modified with Permission: Jones et al., 2018: 7)

\begin{tabular}{|c|c|c|c|c|}
\hline Website Name & $\begin{array}{l}\text { Disability } \\
\text { Category }\end{array}$ & $\begin{array}{l}\text { \# of Apps } \\
\text { on site }\end{array}$ & $\begin{array}{l}\text { \# of mhealth } \\
\text { apps on site }\end{array}$ & Names of Apps \\
\hline $\begin{array}{l}\text { FCC's Accessibility Clearing House } \\
\text { (www.ach.fcc.gov) }\end{array}$ & $\begin{array}{l}\text { Blind / Visually } \\
\text { Impaired }\end{array}$ & 88 & -2 & \\
\hline FCC’s Accessibility Clearing House & Cognitive & 56 & 6 & $\begin{array}{l}\text { Behavior Status, In Case of Emergency } \\
\text { (ICE) personal health information; PE } \\
\text { (Prolonged Exposure) Coach; PTSD Coach; } \\
\text { Seizure Log; Small Talk Pain Scale } \\
\end{array}$ \\
\hline FCC’s Accessibility Clearing House & Mobility & 40 & 3 & ICE; RxMindMePerscription; Seizure Log \\
\hline $\begin{array}{c}\text { Apps for the Deaf and Hearing Impaired } \\
\text { (www.appadvice.com) }\end{array}$ & Deaf / HoH & 14 & 0 & \\
\hline $\begin{array}{l}\text { iOS Apps Developed Specifically for Blind or Low } \\
\text { Vision Users (www.applevis.com) }\end{array}$ & Blind / Low Vision & 112 & 1 & CrowdViz \\
\hline Friendship Circle (www.friendshipcircle.org) & $\begin{array}{l}\text { Autism / Learning } \\
\text { Disabilities }\end{array}$ & 7 & 1 & Behavior Tracker Pro \\
\hline $\begin{array}{l}\text { AFB's Collection of Accessible Apps for Android } \\
\text { (www.afb.org/afbpress/pub.asp?DocID=aw140303) }\end{array}$ & Blind & 10 & 0 & \\
\hline
\end{tabular}

(Solomon, Wynia, and Gostin, 2020: 3). However, there are still priority areas for research on mobile healthcare technology. There is a need to identify the needs, design applications, and create mobile health apps that can address the health disparities and ameliorate the health outcomes among people with disabilities (Jones et al., 2018). Feedback from people with disabilities (Zhou et al., 2020) can be highly valuable for the improvement of conceptualization and design of innovative mobile healthcare technologies to make these apps more accessible for them during this emergency and in the postpandemic period.

\section{REFERENCES}

Godwin-Jones, R. (2011). Emerging technologies: mobile apps for language learning. Language Learning and Technology, 15(2), 2-11

Jones, M., Morris, J. and Deruyter, F. (2018). Mobile Healthcare and People with Disabilities: Current State and Future Needs. Int. J. Environ. Res. Public Health, 15, 515. https://doi.org/10.3390/ijerph15030515

Oberg, A. and Daniels, P. (2013). Analysis of the effect of a student-centered mobile learning instructional method has on language acquisition. Computer Assisted Language Learning, 26(2), 177-196. https://doi.org/10.1080/ 09588221.2011 .649484

Setiawan, M. A., Zhou, L., Alfikri, Z., Saptono, A., Fairman, A., Dicianno, B. E. and Parmanto, B. (2019). An Adaptive Mobile Health System to Support Self-Management for Persons with Chronic Conditions and Disabilities: Usability and Feasibility Studies. JMIR Form Res, 3(2), e12982. https://doi.org/10.2196/12982
Solomon, M., Wynia, M. and Gostin, L. (2020). Covid-19 Crisis Triage-Optimizing Health Outcomes and Disability Rights. The New England Journal of Medicine. https://doi.org/10.1056/NEJMp2008300

Sung, Y.-T., Chang, K.-E. and Liu, T.-C. (2016). The effects of integrating mobile devices with teaching and learning on sudents' learning performance: A meta-analysis and research synthesis. Computers \& Education, 94, 252e275. https://doi.org/10.1016/j.compedu.2015.11.008

Thompson, S. (2018). Mobile technology and inclusion of persons with disabilities. K4D Emerging Issues Report. Brighton, UK: Institute of Development Studies.

Yu, D. X., Parmanto, B., Dicianno, B. E., Watzlaf, V. J. and Seelman, K. D. (2017). Accessibility needs and challenges of a mHealth system for patients with dexterity impairments. Disabil Rehabil Assist Technol, 12(1), 56-64. https://doi.org/10.3109/17483107.2015.1063171

Yu, D., Parmanto, B. and Dicianno, B. (2019). An mHealth app for users with dexterity impairments: accessibility study. JMIR Mhealth Uhealth, 7(1), e202. https://doi.org/10.2196/ mhealth.9931

Zhou, L., Saptono, A., Setiawan, M. A. and Parmanto, B. (2020). Making Self-Management Mobile Health Apps Accessible to People with Disabilities: Qualitative Single-Subject Study. JMIR Mhealth Uhealth, 8(1), 1-15. https://doi.org/ $10.2196 / 15060$ 